\title{
Study of Anisotropic permeability of Coarse-grained soils using Experimental Model and X-ray Diffraction Analysis
}

\begin{abstract}
Background: Permeability is one of the most important physical properties of soil used in water engineering science. In order to carry out this research, we designed and tested a device for measuring the horizontal and vertical permeability in a sample with coarsegrained particles.

Methods: In the present study, four uniform soil samples and three non-uniform samples under different densities and different water loads were selected to test. In this study, to identify the effect of shape factor on permeability of coarse-grained particle, mineralogy of samples was carried out using X-ray diffraction analysis by XRD.

Result: The results of the research show that the permeability in the horizontal direction is often greater than the permeability in the vertical direction and this difference is more pronounced for non-uniform samples compared to uniform samples. The permeability anisotropy rate for uniform samples is between 0.85 and 1.35 and for non-uniform samples in the range of 1.32 to 3.5 .
\end{abstract}

Key words: Anisotropy, Coarse-grained particles, Laboratory research, Permeability, X-ray diffraction analysis.

\section{INTRODUCTION}

Physical and mechanical properties of soils and sedimentary rocks are generally heterogeneous. The anisotropy of hydraulic conductivity of soils has a great influence on the fluid flow and the transmission of contamination. Generally, the hydraulic conductivity is more in the horizontal direction than the hydraulic conductivity in the vertical direction and the hydraulic conductivity anisotropy is shown with a nondimensional parameter $r_{k}$ which is equal to the ratio of the horizontal hydraulic conductivity to the vertical hydraulic conductivity. According to Chapuis et al. (1989), on more than 100 measurements of hydraulic conductivity along with the results of the experiments of Chapuis et al. (1990), Rice et al. (1970) and Leroueil et al. (1990), the anisotropy of the hydraulic conductivity of clays, sands and sedimentary rocks are almost like each other. Recently, simulation of the flow passing through materials is used to predict how to transfer in heterogeneous materials. The LBM method is usually used to model the flow of granular materials. Other devices are also designed to measure the anisotropy of permeability of grainy and sticky soils. Guo et al. (2015) designed a measuring device to obtain the permeability coefficient of grain soils in different directions $\left(0-90^{\circ}\right)$. Jun Ji et al. (2015) designed a modified device for measuring the permeability anisotropy of coarse-grained soils. The degree of permeability anisotropy measured in these devices was influenced by various factors such as particle size, particle arrangement, sample preparation method and porosity rate, as well as hydraulic gradient. The degree of anisotropy of the permeability of homogeneous clays, rocks and granular soils is very similar. It appears to be less than 4. Chapuis et al. (1989) studies show that the sand and gravel anisotropy level is in the range of 0.75 to $4.1 ; 95 \%$ of the anisotropy coefficient is reported in the range of 1.6 to 2.7 . The results
${ }^{1}$ Coastal, Port and Marine Science Engineering, Khorramshahr University of Marine Science and Technology, Iran.

${ }^{2}$ Marine Science Structures, Khorramshahr University of Marine Science and Technology, Iran.

Corresponding Author: M. Bakhtiari, Marine Science Structures, Khorramshahr University of Marine Science and Technology, Iran. Email: mortezabakhtiari@yahoo.com

How to cite this article: Pishro, F., Bakhtiari, M. and Shahnikaramzadeh, N. (2022). Study of Anisotropic permeability of Coarse-grained soils using Experimental Model and X-ray Diffraction Analysis. Agricultural Science Digest. 42(1): 1-7. DOI: 10.18805/ag.D-205.

Submitted: 10-10-2019 Accepted: 11-06-2020 Online: 31-07-2021

of the experiment also show that, with increasing density, this coefficient increases and decreases with increasing porosity. Guo et al. (2015) obtained the maximum permeability anisotropy for homogeneous grained materials equal to 2.5. The results of Jun Jie et al. (2015) experiments on coarse-grained materials show that the horizontal permeability coefficient is 1.2 to 2.28 times the vertical permeability coefficient. Generally, the hydraulic gradient 1-5 better covers the condition of the site. In the present study, a device has been designed for measuring the permeability of coarse-grained soil particles to measure both horizontal permeability and vertical permeability in this device and also the effect of hydraulic gradient and density difference of soil samples have been investigated on the degree of hydraulic conductivity anisotropy.

\section{MATERIALS AND METHODS}

Constant head permeability tests performed using an apparatus that can measure both horizontal permeability 
and vertical permeability. This apparatus meets the required standards (ASTM D5856) for the permeability test device and includes: air valves, inlet and outlet and air valves and porous plates of the same size as the sample. In Fig 1 shows the device designed and constructed to measure horizontal and vertical permeability ASTM (2011a, 2006a).

The dimensions of the measuring device should not be less than 4-6 times the largest effective diameter (D85) of the soil particles used in the test (Wang et al., 2015). Therefore, in this study, the largest grain size is $9.5 \mathrm{~mm}$ and the internal dimensions of the measuring device are $150 \times$ $150 \mathrm{~mm}$, with the length of $173 \mathrm{~mm}$. Due to the effect of boundary conditions, it is proposed that the horizontal and vertical permeability tests can be performed individually, which is the subject of this study, because if vertical permeability testing is to be made, porous plates should be placed at the top and bottom which in this case, if horizontal permeability test is also performed in these conditions, these plates will affect the results. In addition to the water inlet valve, an air valve was also installed in the two sections. The details of the horizontal and vertical permeability measuring device are shown in Fig 2.

\section{Sample preparation}

In order to prepare the samples, the sample should first be dried in the furnace and then the sample is used for both maximum and minimum density tests. After drying, the sample is taken out of the furnace and allowed to cool at the laboratory temperature. This reconstruction method is the best method for simulating the natural sedimentation of the soil (silty sand) with minimum energy (zero drop height), thus preventing the separation of grains as possible. In this method, the ends of the tubed funnel are placed at the bottom of the sampler molding. The sand and gravel gains pour slowly along the axis of symmetry of the machine, with this method giving the most relaxed mode. The sample was compacted in the permeameter into three equal thickness layers (Fig 3).

\section{Tested materials}

The experiments of the present research were performed on four samples with uniform granulation and three nonuniform samples. In Table 1 and 2, the specifications of the uniform and non-uniform samples and in Fig 4 and 5 the grading graph of the uniform and non-uniform materials respectively are shown.

Chapuis et al. (1989) studies show that horizontal permeability is often bigger than vertical permeability and anisotropy permeability defined on Eq. (1) as follows:

$$
r_{k}=\frac{k_{h}}{k_{v}}
$$

Where

$\mathrm{Kh}$ and $\mathrm{Kv}$ are horizontal permeability and vertical permeability, respectively. Therefore, rk is usually larger than one.

\section{$X$-ray diffraction method (XRD)}

The most important analytical methods in this regard are the mineralogy of the samples by X-ray diffraction using

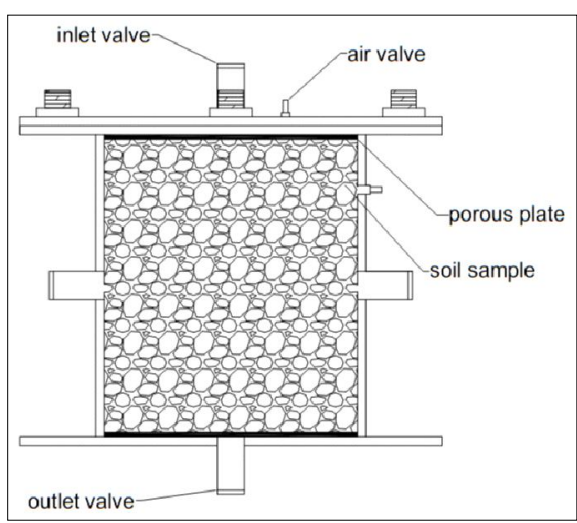

Fig 1: Permeability measurement device.

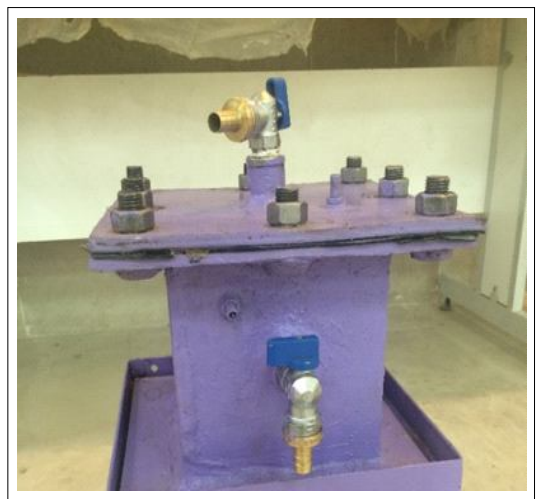

Fig 2: A view of the horizontal and vertical permeability device and porous plates.

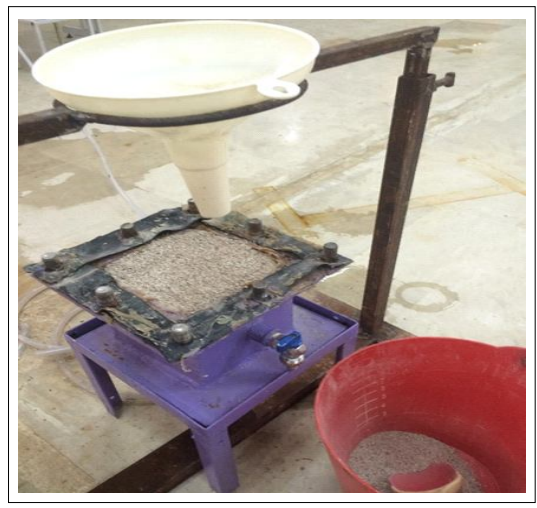

Fig 3: Preparation of the sample in a pouring method.

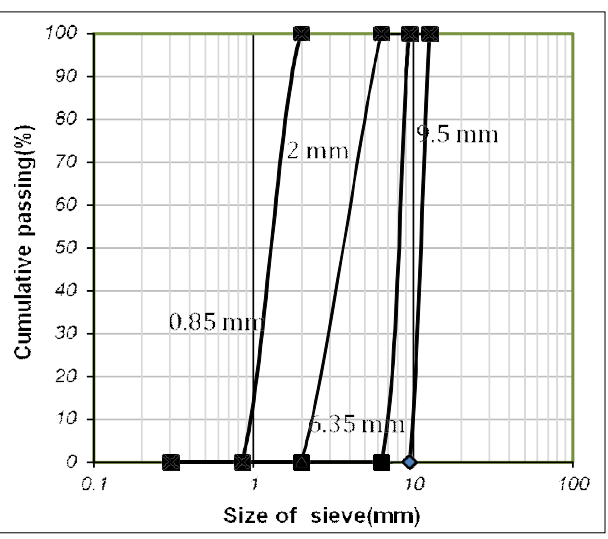

Fig 4: Grading curve of uniform particles. 
$\mathrm{XRD}$, diffraction is a method for studying the structure of crystalline materials, discovered in 1912 by von Lauwe and it was used by William Henry Bragg and William Lawrence Bragg to examine the crystals. Today, this method is widely used to determine the mineralogy of all phases in the studied sample.

\section{Testing results}

The average values of the horizontal and vertical hydraulic conductivity of the four uniform samples and three nonuniform samples, with the same particle size distribution curve were used as the hydraulic conductivities $\mathrm{Kh}$ and $\mathrm{Kv}$. The average anisotropic coefficient rk which were calculated by Eq. (1). The average horizontal hydraulic conductivity for uniform samples was between 0.85 to 1.35 times more than that of vertical one and for non-uniform samples in the range of 1.32 to 3.5 . The anisotropic coefficient measured by the modified instrument is 1 to 5 (Wang et al., 2015). The mean anisotropic coefficient from our samples was bigger than the mean measured by the above research.

\section{RESULTS AND DISCUSSION} Investigation uniform samples

According to Wang et al. (2015) experiments on the five coarse-grained soil samples, the critical hydraulic gradient was determined. Particles are beating violently when the effluent is muddy. In this study, the effect of hydraulic gradient on horizontal and vertical permeability in Fig (6) to (9) is shown for uniform samples in minimum and maximum conditions.

As shown in Fig 6, under the conditions of the minimum porosity coefficient the vertical permeability coefficient decreases with increasing hydraulic gradient up to $(H / L=4)$ and then the process of change is almost constant. Therefore, the results of the experiment are becoming constant with increasing the gradient. The behavior occurred for horizontal permeability is also the same as the vertical permeability coefficient. In this case, under the conditions of the minimum porosity coefficient, the horizontal permeability coefficient decreases with increasing hydraulic gradient up to $(H / L=4.2)$ and then the process of change is almost constant. As seen in Fig (8) and (9), the behavior

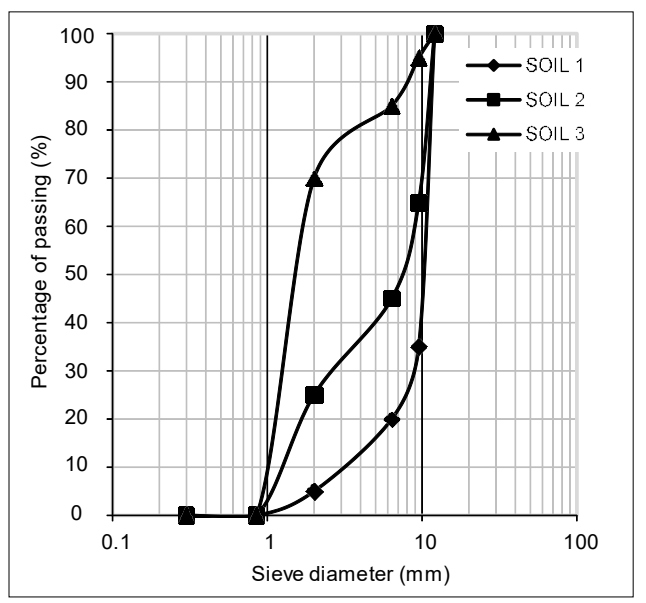

Fig 5: Grading curve of non-uniform particles. observed in both vertical and horizontal permeability states at maximum porosity conditions is the same conditions for minimal porosity. In this case, first, by increasing the hydraulic gradient to the same previous level, the

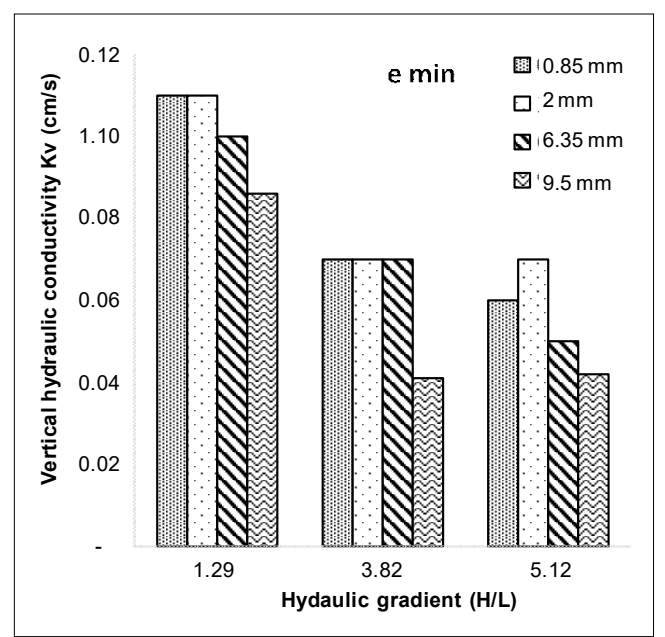

Fig 6: Vertical permeability coefficient versus the hydraulic gradient for uniform samples.

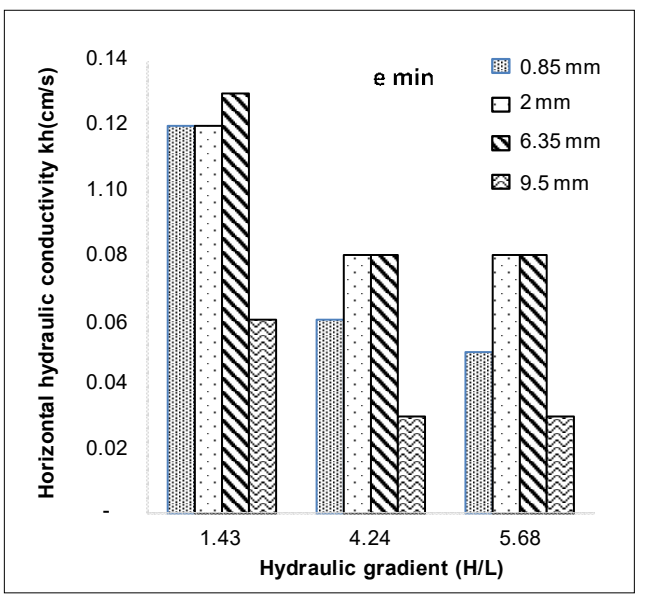

Fig 7: Horizontal permeability coefficient versus hydraulic gradient for uniform samples.

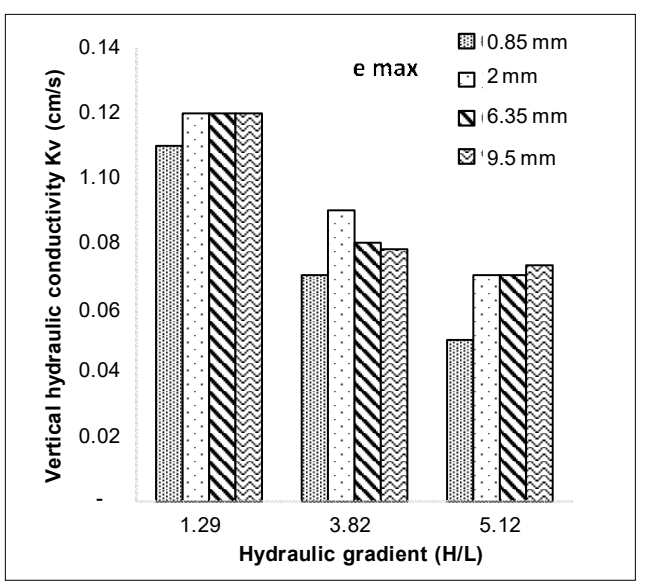

Fig 8: Vertical permeability coefficient versus the hydraulic gradient for uniform samples with maximum porosity. 
permeability coefficients decreased and then had a constant value. Also, by increasing the hydraulic gradient, smaller specimens will be removed along with the outlet stream. In order to study the effect of sample porosity on permeability coefficient, we plotted vertical and horizontal permeability coefficients simultaneously with porosity. The Fig (10) to (13) have shown these graphs.

The permeability anisotropy coefficient is defined as the ratio of the horizontal permeability coefficient to the vertical permeability coefficient. Fig 14 shows the degree of permeability anisotropy coefficient versus porosity for different samples.

Investigating the results show that with the increase of porosity, the permeability anisotropy coefficient is reduced for uniform samples and this coefficient is in the range of 0.89 to 1.35 for uniform samples. The study of previous studies shows that the degree of anisotropy of the permeability of homogeneous clays, rocks and granular soils is very similar and its rate is less than 4 . Chapuis and Gill (1989) studies show that the anisotropy in sand and gravel in the range of 0.75 to 1.4 is $95 \%$ of the anisotropy coefficient in the range of 1.6 to 2.7 . The results of the experiment also show that, by increasing the density, the anisotropy

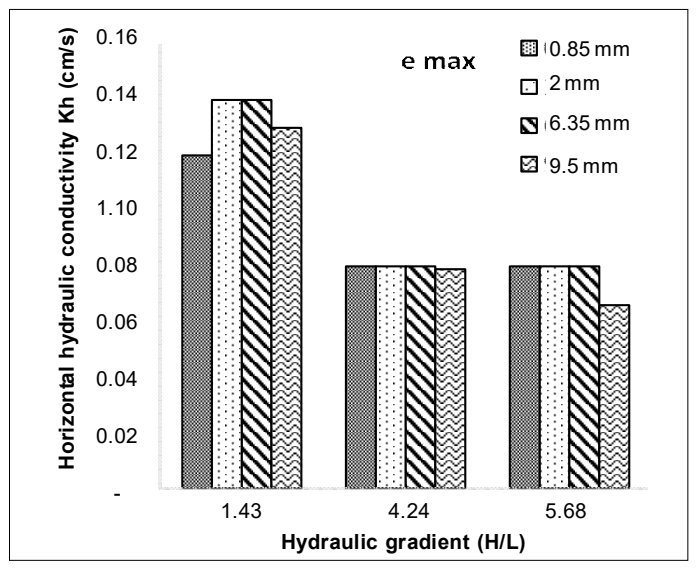

Fig 9: Horizontal permeability coefficient versus the hydraulic gradient for uniform samples with maximum porosity.

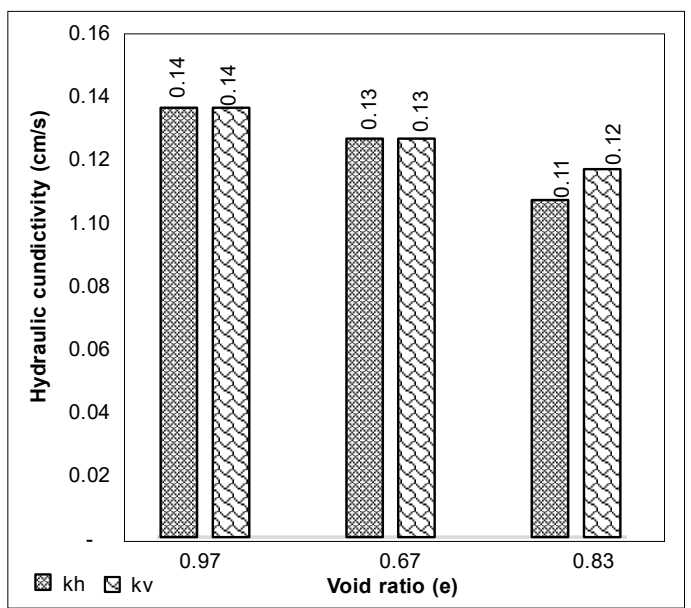

Fig 10: Horizontal and vertical permeability coefficients for a sample- uniform with a diameter of $0.85 \mathrm{~mm}$. coefficient increases and decreases with increasing porosity. Following Gue et al. (2015), horizontal hydraulic conductivity Ottawa sand with Porosity ratio 0.53 , is 1.24 to 1.44 time's vertical hydraulic conductivity. The average anisotropic hydraulic conductivity of uniform samples is lower than that of Ottawa sand in Gue et al. (2015).

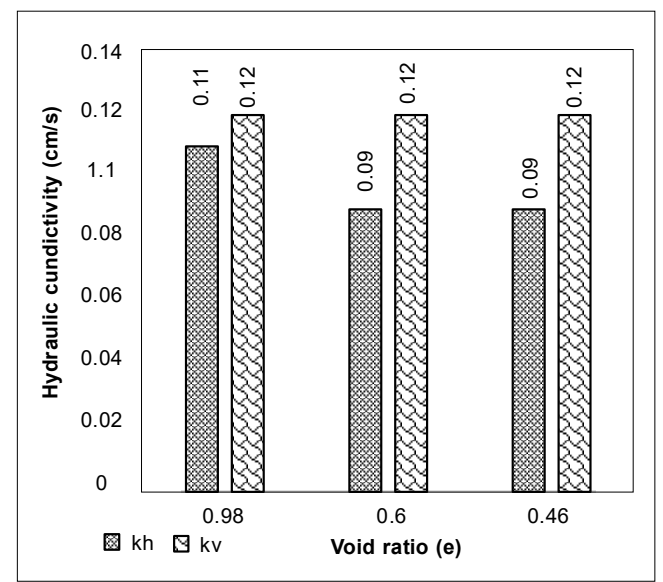

Fig 11: Horizontal and vertical permeability coefficients for a sample-uniform with a diameter of $2 \mathrm{~mm}$.

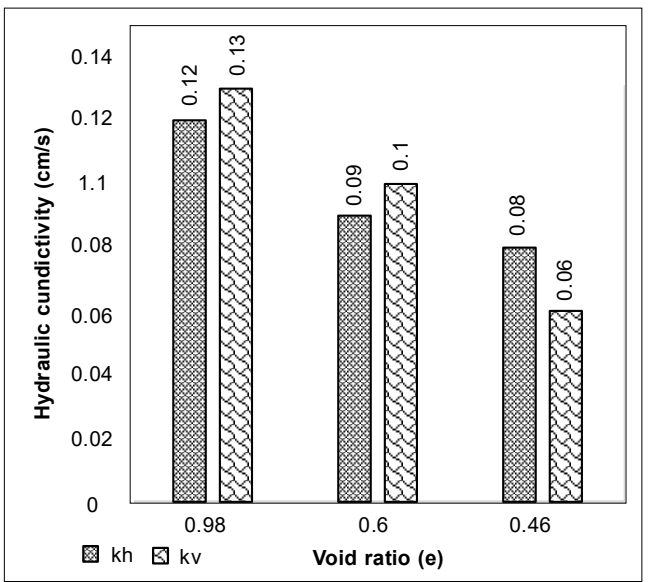

Fig 12: Horizontal and vertical permeability coefficients for a sample-uniform with a diameter of $6.35 \mathrm{~mm}$.

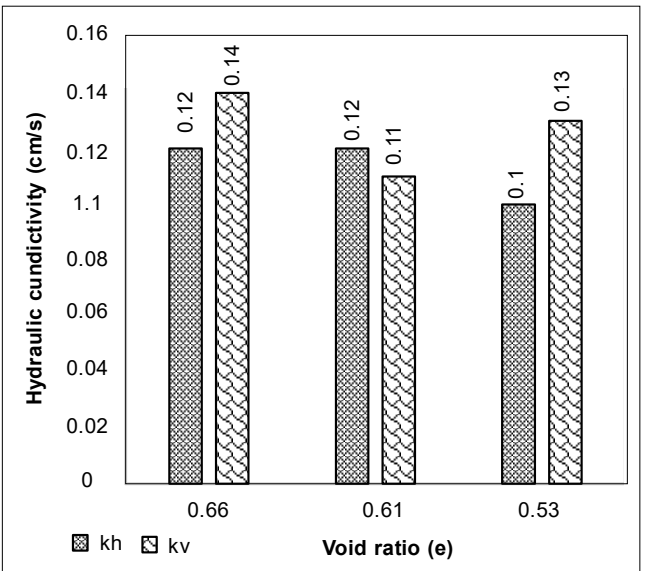

Fig 13: Horizontal and vertical permeability coefficients for a uniform sample with a diameter of $9 \mathrm{~mm}$. 


\section{Investigating non-uniform samples}

In Fig (15) to (16), the effect of hydraulic gradient on horizontal and vertical permeability is shown for uniform samples in minimum and maximum conditions of density. The findings show that the results are similar for all of the studied scenarios. As for vertical permeability, both minimum and maximum porosity in the hydraulic gradient is about 3.8 and for the vertical permeability, for both the minimum and maximum porosity to the hydraulic gradient of about 4.1 , with the increase of the hydraulic gradient, the permeability coefficient is reduced and after these values, with the increase of the hydraulic gradient, the permeability coefficient is almost constant.

Investigations show that the horizontal permeability coefficient in the maximum porosity of 0.67 , in comparison with the vertical permeability coefficient, increases by $26.66 \%$ and in the minimum porosity of 0.43 , the horizontal permeability coefficient is $22.5 \%$ higher than the vertical permeability coefficient. It is also worthwhile to note that the permeability anisotropy rate for sample (1) is between 1.32 and 1.8. Also results show that with increasing porosity, the permeability coefficients in all cases are increased in both horizontal and vertical states. The horizontal permeability coefficient in the maximum porosity of 0.84 , compared to the vertical permeability coefficient of, increases by $28.58 \%$ and in the minimum porosity $(0.41)$, the horizontal permeability coefficient was $36.36 \%$ higher than the vertical permeability coefficient, as well as the permeability anisotropy for sample (2) it is between 1.32 and 2.81. The results obtained in this case are similar to those of the two previous cases, so that in all of the studied states, with increase in porosity, the permeability coefficients increased in both horizontal and vertical states. The results show that the horizontal permeability coefficient in the maximum porosity of 0.82 compared to the vertical permeability coefficient, increases as $61.5 \%$ and in the minimum porosity condition 0.56 , the horizontal permeability coefficient is $60 \%$ higher than the vertical permeability coefficient (Fig 17). Also,

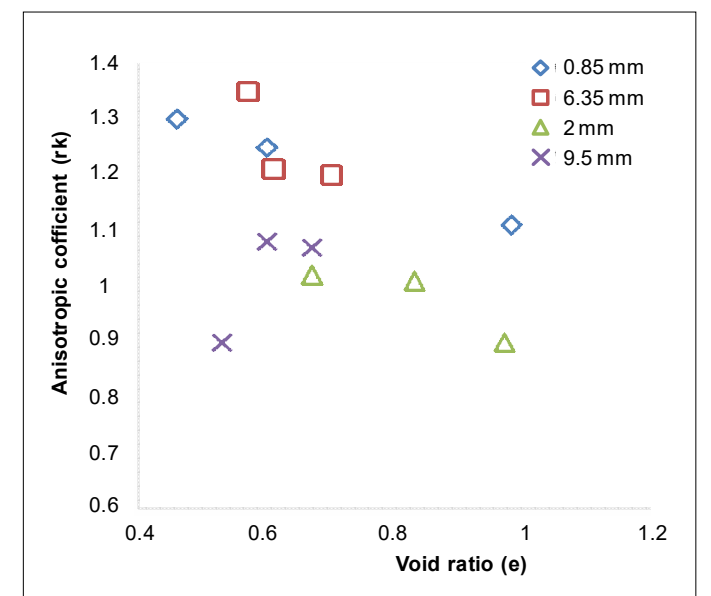

Fig 14: The degree of permeability anisotropy versus porosity of uniform samples. the permeability anisotropy for sample (3) is between 2.23 and 3.5. Fig (18) shows the relationship between fine particles (particles smaller than $(4.75 \mathrm{~mm})$ and anisotropic coefficients for the samples tested in this experiment and

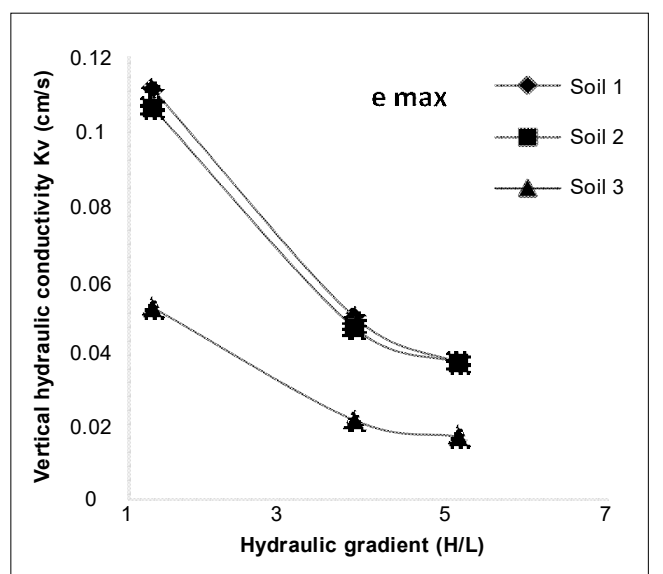

Fig 15: Vertical permeability coefficient of non-uniform samples versus hydraulic gradient under maximum porosity conditions.

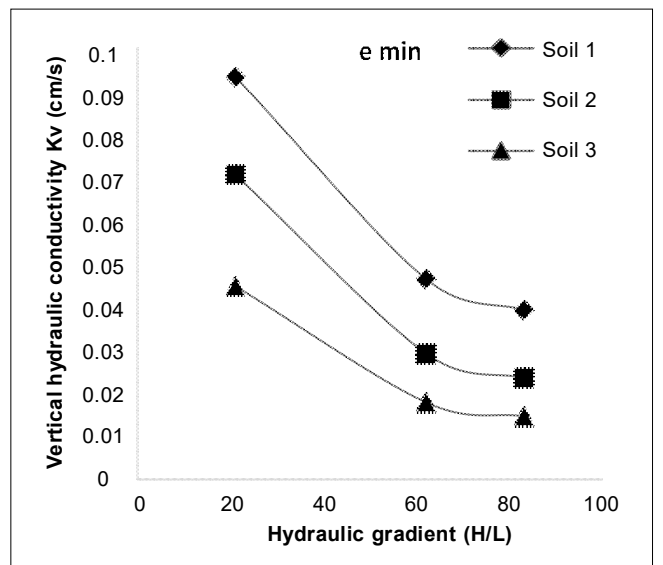

Fig 16: Vertical permeability coefficient of non-uniform samples versus hydraulic gradient in manimum porosity conditions.

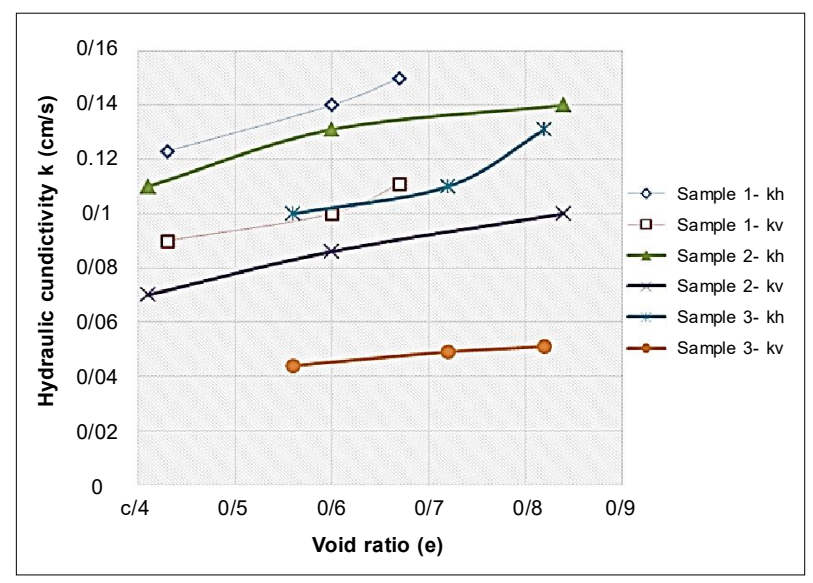

Fig 17: Vertical and horizontal permeability coefficient versus porosity for the sample (3). 


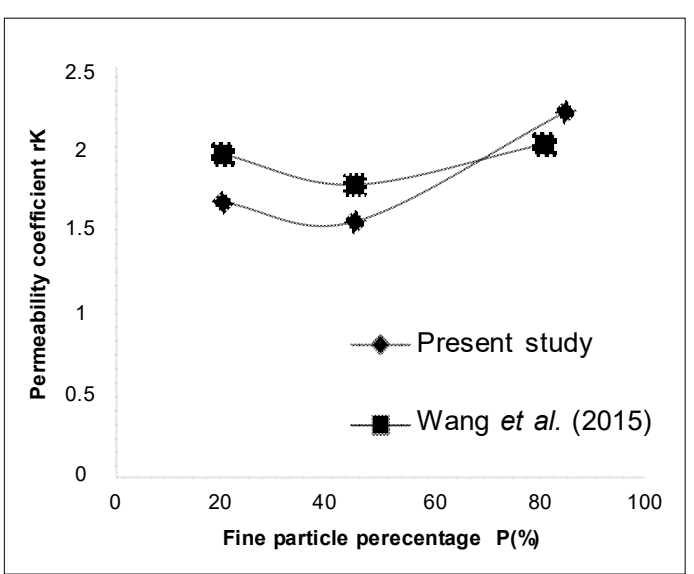

Fig 18: Correlation coefficient with fine particles percentage, $\mathrm{P}(\%)$.

Table 1: Distribution of particles according to the results of the screening test.

\begin{tabular}{lccc}
\hline Sample & D50 & Cu & Cc \\
\hline 1 & 0.85 & 1.63 & 0.74 \\
2 & 2 & 1.81 & 0.95 \\
3 & 6.35 & 1.2 & 0.95 \\
4 & 9 & 1.10 & 1.007 \\
\hline
\end{tabular}

Table 2: Distribution of particles According to the results of the screening test.

\begin{tabular}{lccccc}
\hline Sample & D10 & D60 & D30 & Cu & Cc \\
\hline 1 & 2.85 & 12 & 9 & 4.2 & 2.36 \\
2 & 1.16 & 8.8 & 2.75 & 7.85 & 0.74 \\
3 & 0.92 & 1.85 & 1.28 & 2 & 0.96 \\
\hline
\end{tabular}

Table 3: Mineralogy tests result.

\begin{tabular}{lcc}
\hline Sample type & & Mineral type \\
\hline Uniform samples & Sample 1 & Carbonate \\
& Sample 2 & Carbonate \\
& Sample 3 & Silicate \\
& Sample 4 & Clay \\
Non uniform samples & Sample 1 & Silicate+ carbonate \\
& Sample 2 & Silicate \\
& Sample 3 & Clay+ Silicate \\
\hline
\end{tabular}

the results are compared with the results of Wang et al. (2015) experiments on the sample have been compared with the minimum porosity.

The results show that the amount of anisotropic of hydraulic conductivity by increasing the percentage of fine particles to about $45 \%$ of fine particles decreases and then increases, so that with an increase of about $45 \%$ of fine grained, the anisotropic hydraulic conductivity increases by 34.12 percent. The comparison between the results of the present research and the research by Wang et al. (2015) is in good agreement (Bernaix et al., 1982).

The results of mineralogical studies of the sediment samples are presented in Table (3). The obtained data show that minerals such as calcite and quartz are present in all the tested specimens as main mineral components. In addition, mineral compounds as Albite and Muscovite-llite are also observed in $90 \%$ of the tested samples as the main mineral phase. Finally, based on the results of mineralogical studies of sediments collected from the Abadan coast, it can be concluded that the mineralogy of these coasts is generally classified in three major groups: the carbonate mineral group, the silicates mineral group and clay minerals: The clay mineral group is one of the components of coastal sediments that has been commonly seen as the dominant component in the main mineralogical phase of the studied regions.

According to the investigations carried out for coarsegrained samples used in this study, particles with carbonate minerals have a higher horizontal and vertical permeability coefficient than particles of silicate minerals. Also, the amount of this coefficient for particles composed of silicate minerals is more than particles with mineral clay. We know that one of the most important factors in determining the coefficient of permeability of coarse-grained particles is the factor of the shape. As carbonate minerals are a group of minerals in which there is a 2-CO3 base. This base is in the form of a triangle with oxygen in the corners and carbon in the middle of it. In the structure of carbonates, these triangles are linked by cations. Crystal crystals of clay minerals are generally in the form of wide, thin, hexagonal shapes the results of compare between this study and past studies are presented in Table 4.

Table 4: Compare between past and present study (Bernaix et al., 1982).

\begin{tabular}{llcc}
\hline Soil type & Method & The anisotropy rate & Researcher \\
\hline Sand and gravel & Device for measuring the horizontal and vertical permeability & $0.75-1.7$ & Pare et al. (1982) \\
Gravel & Device for measuring the horizontal and vertical permeability & $0.87-1.83$ & Chapuis and Gill (1989) \\
Gravel & Device for measuring the horizontal permeability in two way & $1.04-1.06$ & Latini (1967) (Bernaix et al., 1982) \\
Gravel & Device for measuring the horizontal permeability in two way & $0.93-1.36$ & Fontojen (1969) (Bernaix et al., 1982) \\
Mica & Device for measuring the horizontal permeability in two way & 1.9 & Fontojen (1969) (Bernaix et al., 1982) \\
Gravel & Air injection & 0.38 & Wit (1966) \\
Gravel & Device for measuring the horizontal and vertical permeability & Horizontal permeability & Present study \\
& & Vertical permeability & \\
& & (1.32-3.5) & \\
\hline
\end{tabular}




\section{CONCLUSION}

The final results can be summarized as follows:

1) Permeability in the horizontal direction is often more than the permeability in the vertical direction. This difference is more apparent for non-uniform samples compared to uniform ones. 2) With the increase of the hydraulic gradient, the velocity of the flow passing through the samples increases and at its maximum reaches $0.005 \mathrm{~m} / \mathrm{s}$, in this case, the Reynolds number is increased and the Darcy rule is invalid and the flow can be turbulent in this case.

3 ) The degree of permeability anisotropy for uniform samples has values close to 1 and range from 0.85 to 1.35 in this research and the degree of anisotropy decreases with increasing porosity. The permeability anisotropy obtained is in the range of 1.32 to 3.5 , in other words, the horizontal and vertical permeability difference for non-uniform samples is greater than the uniform samples and for the smaller sample (sample 3 ), the anisotropy is more.

4) As the uniformity coefficient increases, the permeability anisotropy decreases. Also, in non-uniform samples, the permeability anisotropy increases with increasing percentage of fine particles (particles with a diameter less than $4.75 \mathrm{~mm}$ ). 5) According to the above items, it can be said that the permeability of carbonate minerals is greater than silicate and clay minerals.

\section{ACKNOWLEDGEMENT}

The authors of this article thank the Khorramshahr University of Marine Science and Technology for creating the conditions for conducting this research.

\section{REFERENCES}

ASTM. (2006a). ASTM D4253-00: Standard test methods for maximum index density and unit weight of soils using a vibratory table. ASTM int., West Conshohocken, PA. doi:10. 1520/ D4253-00R06.
ASTM. (2011a). Standard D2434 - Permeability of Granular Soils (Constant Head). ASTM Annual CDs of Standards, 04. 08. West Conshohocken, PA.

Bernaix, J., Ares, R., Cabot, L., Garzon, M. (1982). Large scale permeability and filter tests at lg3", procceding of the ivth congress on large dams, Rio de Janeiro. Q.55, R.7. pp. 103-122.

Chapuis, R.P. (2004). Predicting the saturated hydraulic conductivity of sand and gravel using effective diameter and void ratio. Can Geotech J. 41: 787-795.

Chapuis, P. and Gill, D.E. (1989). Hydraulic anisotropy of homogeneous soils and rocks: Influence of the densification process. Bull. Int. Assoc. Eng. Geol. 39: 75-86.

Guo, P., Liu, Y. and Stolle, D. (2015). Limit of Anistropic Hydraulic Conductivity Ratio of Homogeneous Granular Materials Soil science society of America 5585 Guilford Rd., Madison. WI 53711 USA.

Leroueil, S., Bouclin, G., Tavenas, F., Bergeron, L. and La Rochelle, P. (1999). Permeability anisotropy of natural clays as a function of strain. Can. Geotech. J. 27: 568-579. DOI: 10.1139/t90-072.

Pare, J.J., Ares, R., Cabot, L., Garzon, M. (1982). Large scale permeability and filter tests at $\lg 3$. procceding of the ivth congress on large dams, rio de janeiro, Q.55, R.7. pp.103122. 1982.

Rice, P.A., Fontugne, D.J., Latini, R.G., Bardhun, A.J. (1970). Anisotropic permeability in porous media. Industrial and Engineering Chemistry. 62(6): 23-31.

Wang, J. and Qiu, Z. (2015). Anisotropic hydraulic conductivity and critical hydraulic gradient of a crushed sandstone-mudstone particle mixture, Marine Georesources and Geotechnology. 35(1): 89-97.

Wit, K.E. (1966). Apparatus for measuring hydraulic conducitivity of undisturbed soil sample. ASTM STP. 417: 72-83.

Witt, K.J., Brauns, J. (1983). Permeability-anisotropy due to particle shape. Journal of Geotechic Engineering. 109(9): 11811187. 